ARTICLE HISTORY: Received: August: 6, 2021 Accepted: September 27, 2021 Published: October 4, 2021

УДК 8

КОМПЛЕКСНЫЙ АНАЛИЗ ТЕКСТА КАК СРЕДСТВО ФОРМИРОВАНИЯ КОММУНИКАТИВНОЙ
КОМПЕТЕНЦИИ СТУДЕНТОВ В ПРОЦЕССЕ ИЗУЧЕНИЯ ДИСЦИПЛИНЫ «РУСКИЙ ЯЗЫК И
КУЛЬТУРА РЕЧИ»

Кулумбегова Людмила Владимировна

Доцент кафедры русского языка,

Юго-Осетинский государственный

университет им. А.А. Тибилова

2. Цхинвал. Южная Осетия

\title{
COMPLEX TEXT ANALYSIS AS A MEANS OF FORMING STUDENTS COMMUNICATIVE COMPETENCE IN THE COURSE OF STUDYING THE DISCIPLINE" RUSSIAN LANGUAGE AND SPE
}

Kulumbegova Lyudmila Vladimirovna Associate Professor of the Russian Language Department,

A.A. Tibilov South Ossetian State

University, Tskhinval. South Ossetia

\begin{abstract}
Аннотация. Статья посвящена комплексному изучению текста , позволяющему студентам совершенствовать свою речевую культуру в процессе изучения русского языка. По мнению автора работы, актуальность данной работы определяется недостаточным уровнем сформированности коммуникативной компетенции студентов и необходимостью формирования их коммуникативных навыков.

Особый акцент в работе сделан на том, что отличительной чертой коммуникативной компетенции является способность развития успешной активности личности в социальном окружении, так как современное общество требует от выпускника вуза наличия высокого уровня культуры грамотного общения.

Abstract. The article is devoted to the complex study of the text, which allows students to improve their speech culture in the process of learning Russian. According to the author, the relevance of this work is determined by the insufficient level of formation of students ' communicative competence and the need to form their communication skills.

Special emphasis is placed on the fact that the distinctive feature of communicative competence is the ability to develop successful activity of a person in a social environment, since modern society requires a high level of culture of competent communication from a University graduate.

Ключевые слова: текст, изучение и анализ текста, развитие связной речи студентов и их коммуникативной компетенции, устная и письменная речи

Keywords: text, study and analysis of text, development of students ' coherent speech and their communicative competence, oral and written speech
\end{abstract}

Высокий уровень речевой культуры - неотъемлемая черта современного выпускника любого вуза. Человек достигает высшего уровня речевой культуры, если обладает правильной и связной речью. Это значит, что он не только не допускает ошибок, но и умеет наилучшим образом строить высказывания в соответствии с целью общения, отбирать наиболее подходящие в каждом случае слова и конструкции, учитывая при этом, к кому и при каких обстоятельствах он обращается. В настоящее время в системе высшего образования обучение русскому языку как важнейшему элементу общей и профессиональной культуры и средству профессионального общения приобрело особую значимость.

Это актуально в настоящее время, так как современному обществу требуются не просто специалистыпрофессионалы, обладающие определенными знаниями, умениями и навыками, а люди, способные к самосовершенствованию. Только они, обладающие высокой профессиональной компетентностью, умеющие творчески работать, находящиеся в постоянном поиске, могут в полной мере осуществить свое творческое и профессиональное предназначение.

В данном аспекте дисциплины «Русский язык», Русский язык и культура речи», «Культура речи» непосредственно нацелена на повышение уровня практического владения современным русским литературным языком студентов любого вуза. 
Нельзя не согласиться с авторами книги «Коммуникативная культура» [3, с.10], что«...коммуникативная компетенция - основа практической деятельности человека в любой сфере жизни».

Действительно, современные условия требуют от выпускника вузов - будущих специалистов в той или иной области, высказываний в правильно построенной форме, как в устной, так и письменной речи. Согласно ФГОС ВО развитие коммуникативной способности и установка на использование этой способности - главный образовательный результат освоения русского языка учащимися на всех ступенях обучения. А именно, способность осуществлять «...деловую коммуникацию в устной и письменной формах на государственном языке Российской Федерации, а также способность воспринимать межкультурное разнообразие общества в социально-историческом, этическом и философском контекстах [12].

В последние годы педагоги часто сталкиваются с тем, что у большинство обучаемых испытывают затруднения в составлении связных высказываний (как устных, так и письменных), аргументации своего высказывания и т.д. Все эти факты в конечном счете становятся барьером для свободной коммуникации молодых людей друг с другом. Как правило, студенты стараются заменить живую речь «виртуальной» или же невербальными способами общения, чаще жестами. В этой связи одной из проблем современного вузовского образования в части изучения русского языка является развитие коммуникативной компетенции студентов.

Именно сейчас обучение студентов коммуникативной компетенции приобретает особую значимость, так как уровень национальной языковой культуры в целом заметно снижается. Мы все чаще сталкиваемся с небрежным обращением с русским языком. Это наблюдается и в средствах массовой информации, и в публицистике, и особенно в повседневном общении. Коммуникативная направленность в изучении языка служит не только формированию навыков общения, но и развивает общую образовательную культуру личности молодого человека.

Обучение русскому языку должно способствовать развитию мышления, пробуждать у них любовь к родной речи, способность к анализу языковых явлений, а также к умению наблюдать речь. В решении этих задач огромное значение имеет комплексная работа с текстом, а соответственно разные виды разбора языкового материала, которые различаются по содержанию, объему и способу выполнения.

В методике обучения русскому языку текст является ведущей единицей словесной коммуникации. И это не случайно, поскольку именно работа с текстом способствует оптимальному усвоению языка: «Развивать связную речь... - это значит научить воспринимать и создавать коммуникативно ориентированные тексты в процессе трудовой, учебной, бытовой, общественной деятельности, то есть научить... полноценно общаться» [14, с.103].

В данной работе под комплексным анализом текста мы подразумеваем обязательный вид работы с текстом, позволяющий осуществить системный подход к изучению языка. Другими словами, рассмотрение текст в разных аспектах языкознания, и прежде всего речеведческого.

Можно утверждать, что комплексный анализ текста - это интересный и в то же время продуктивный вид работы, при котором осуществляется функциональный и системный подход к изучению языка. Работа с текстом развивает у обучаемых языковую интуицию, способствует устранению различных видов ошибок, влияющих на понимание смысла сказанного или написанного автором. Кроме того, анализ текста помогает до конца понять особенности текста и грамотно его пересказать (в том числе и письменно), сохраняя при этом его своеобразие.

Это способствует формированию коммуникативной компетенции, которая предполагает «способность средствами изучаемого языка осуществлять речевую деятельность в соответствии с целями и ситуацией общения в рамках той или иной сферы деятельности» [8].

Таким образом, главное направление в обучении - не только полученные знания обучаемых, а применение их на практике, то есть в жизненных ситуациях. Как мы уже отмечали ранее, компетенция и грамотность сегодня - первые причины успешного общения в любой области нашей жизни. Отсутствие одного из факторов приводит к множеству конфликтов в общении. Получается, чтобы быть успешным, нужно быть активно коммуникативным, социально компетентным, а также общественно адаптированным, способным продуктивно взаимодействовать в процессе общения.

Для формирования коммуникативной компетенции на занятиях русского языка необходимо проводить специальные упражнения, различные ситуации, разнообразные методы и приемы работы, способствующие организации продуктивного учебного процесса в соответствии с требованиями образовательного стандарта.

Под комплексным анализом понимаются специальные виды упражнений с текстом, выполнение которых позволяет осуществить системный подход к изучению языка, т.е. рассмотреть текст с разных аспектов языкознания.

Предлагаются следующие определения комплексного анализа текста:

«...Комплексный анализ текста - это вид работы, при котором осуществляется функциональный и системный подход к изучению языка, а также ярко выявляются межпредметные связи» [4].Он предполагает целостное рассмотрение фактов языка в единстве с разными разделами языкознания (о чем пишет М. Р. Львов). «Кроме того, анализ текста необходим для выполнения всех форм работы, связанных с трансформацией текста, - от редактирования и составление плана до изложения» [8]. Именно данная синтаксическая единица помогает выступать в своей функциональной роли любой языковой единице (звукам, словам, морфемам, 
словосочетаниям, предложениям). В целом же «... текст является одним из средств создания на занятиях словесности речевой среды, направленной на развитие коммуникативных способностей обучаемых», - отмечает Малюшкин А. Б. [6].

Известно, что текст как речевое произведение обладает двумя сторонами: выражением и содержанием. Эти стороны взаимосвязаны и взаимозависимы. Поэтому на занятиях следует обращать внимание студентов на связи построения в тексте и способы создания его как единого речевого произведения.

Чтобы понять текст, надо не просто усвоить его содержание, а определить цель его создания. Любой анализируемый текст не должен быть бессмысленным. Анализ всегда должен предполагать цель: С какой целью? Зачем? Для чего? «Подчинять анализ цели - это значит через анализ формальных элементов произведения вести к пониманию его содержания, смысла» [14, с. 102]. Важно через анализ раскрыть то, что без него осталось бы незамеченным.

Во время работы с текстом целесообразно использовать все виды лингвистического разбора: фонетический (чтение с определенной интонацией); лексический (выяснение значения и смыслов слова); морфемный, словообразовательный и этимологический (для разъяснения и уточнения значения слова); морфологический и синтаксический (для уточнения смыслов предложений); стилистический (для построения образов героев, понимания особенностей жанра и композиции текста).

Художественный текст - сложная синтаксическая единица, включающая в себя идейно - эстетическую, жанрово - композиционную и языковую составляющие. Чтобы понять духовное богатство писателей, необходимо рассматривать их тексты в широком смысле. Поэтому перед учителями русского языка лежит непростая задача - помочь учащимся научиться воспринимать и понимать текст, а также высказывать по его поводу собственное мнение.

Примером такого анализа может являться следующий текст.

Перед самым восходом солнца на поляну ложится первый мороз.

Притаиться, подождать у края - что там делается на лесной поляне!

В полумраке рассвета приходят невидимые лесные существа и потом начинают по всей поляне расстилать белые холсты.

Первые же лучи солнца, являясь, убирают холсты, и остается на белом зеленое место. Мало-помалу белое все растает, и только в тени деревьев и кочек долго еще сохраняются беленькие клинышки.

На голубом небе между золотыми деревьями не поймешь, что творится: уносит ветер листы или стайками собрались мелкие птички и несутся в теплые далекие края.

Ветер - заботливый хозяин. За лето везде побывает, и у него даже в самых чистых местах не остается ни одного незнакомого листика. А вот осень пришла - и заботливый хозяин убирает свой урожай. Листья, падая, шепчутся, прощаясь навек. У них ведь так всегда: раз ты оторвался от родимого царства, то и прощайся, погиб...

Предполагаемые вопросы для анализа данного художественного текста:

(М. Пришвин «Осенние листья»)

1. О чем рассказал писатель, природу? Какое чувство вызвал у него замерзиий и притихший лес?

2. Что особенно поражает писателя в природе? Почувствовали ли вы его чувства?

3. Прочитайте вслух текст. Усльлшали ли вы повторы звуков? С какой целью автор использует прием звуковых повторов: для создания образной картины, придания звуковой выразительности или для связи слов в тексте?

4. Есть ли в тексте выразительные средства речи? Выпишите их в тетрадь. Прочитайте текст без них. Как, по-вашему, меняется описание без них? [9, с. 130].

5. Из текста выпишите 5 двусоставных, распространенных предложений и 5 односоставных. Разберите ux no cocmaвy.

6. Придумайте заголовок к тексту.

В качестве самостоятельной работы можно предложить студентам продолжить текст и придумать свою концовку.

Любой художественный текст олицетворяет в себе образ или систему образов. Так, в данном отрывке представлены образы пейзажей. Любой из художественных образов выбирается автором из желания вызвать у читателя определенные чувства, мысли, из стремления в чем-то убедить его (на примере вопросов 1-2 по М. Пришвину «Осенние листья»).

Таким образом, «анализ художественного текста должен способствовать углубленному его прочтению, проникновению в мысль художника, пониманию внутреннего смысла произведения» [9, с. 250].

Как мы видим, формулируя задания к тексту, нужно придерживаться определенной последовательности. Сначала - вопросы и задания, направленные на осмысление содержания и восприятия текста:

- Прочитайте данный текст (отрывок). О чем он?

- Озаглавьте текст (если текст имеет название, подумайте, почему автор назвал его именно так).

- Укажите количество микротем, составьте план текста. 
Что касается плана текста, то можно дать готовый, но с нарушением хронологического порядка. Студенты должны выстроить фабулу отрывка.

Затем должны быть задания речеведческого характера, включающие такие понятия, как стиль, тема, основная мысль, способы и средства связи между предложениями:

- К какому функииональному стилю и типу речи принадлежит текст? Докажите это.

- Определите тему и идею текста.

- Как связаны части текста? Как соотносятся его начало и конеи?

Выстраивать задания таким образом необходимо, поскольку читательское восприятие от этого углубляется, «то, что воспринималось на интуитивном уровне, становится более осмысленным» [11, с. 31].

За речеведческими заданиями следуют подбирать задания языкового характера, отражающие изучение системы языка: по фонетике, лексике, грамматике. Немаловажную роль играют задания, направленные на совершенствование словарного запаса учащихся. Например, словарная работа, связанная с заменой заимствованных слов словами собственно русскими, или же слов, эмоционально окрашенных, словами с нейтральной окраской, подбором синонимов, антонимов, омонимов. Работа со словом и его значением, как лексическим, так и грамматическим - основа развития речи.

Наконец, завершающими заданиями при комплексном анализе текста должны быть вопросы по орфографии и пунктуации, разные виды разбора, составление схем предложений, выполнение которых способствует развитию орфографической и пунктуационной зоркости студентов.

Если к одному тексту предлагается много заданий, то это не означает, что каждый студент должен выполнить непременно все. В процессе комплексной работы с текстом у обучаемых появляется возможность выбора тех вопросов и заданий, которые он считает для себя наиболее интересными.

Таким образом, грамотно организованная работа в ходе комплексного анализа текста даёт возможность обеспечить на занятиях органическую взаимосвязь изучения нового материала и повторения, помогает глубоко проникнуть в содержание текста, а также развивает коммуникативные навыки студентов.

Кроме того, комплексный анализ текста позволяет обучаемым не только показать теоретические знания, но и выразить свое понимание текста посредством творческих заданий (написание эссе или сочинения).

Комплексный анализ текста, проводимый на занятиях русского языка, дает возможность педагогу рассматривать вопросы лингвистики, обеспечивает системное повторение.

Следовательно, грамотно построенная работа по комплексному анализу текста способствует глубокому проникновению в содержание текста, а также развивает коммуникативные, лингвистические и творческие способности студентов.

\section{СПИСОК ЛИТЕРАТУРЫ}

1. Алексеева, М.М. Методика развития речи /М.М.Алексеева, В.И.Яшина. - М.: Просвещение, 2013. - С. 192.

2. Загвязинский В. И. Современная образовательная ситуация и задачи модернизации российского образования// Народное образование. 2012. №5. С.10-11.

3. Ипполитова Н.А. Развитие речи и повышение грамотности // Русский язык в школе. 2017. № 5. - С. 8 15.

4. Комплексный анализ текста на уроках русского языка [Электронный ресурc] URL: http://pandia.ru/text/78/064/10146.php (дата обращения:15.03.2017).

5. Кохтев Н.Н. Сочинение: работа над содержанием и языком. - М.: МГУ. 2014. - 80 с.

6. Малюшкин А. Б. Комплексный анализ текста. М., 2008. -110 с.

7. Методические рекомендации «Анализ художественного текста на уроках словесности» [Электронный pecypc] URL: http://gigabaza.ru/doc/94264-pall.html (дата обращения: 15.02.2017).

8. Методика комплексного анализа текста [Электронный ресурс] URL: http://kopilkaurokov.ru/literatura/uroki/mietodika-komplieksnogho-analiza-tieksta-na-urokakh-litieratury _дата обращения: 03.03.2017).

9. Михайлова Е.В. Тесты и тексты для комплексного анализа текста.-М.: Вако. 2007.- 256 с.

10. Мурзин Л.Н., Штерн А.С. Текст и его восприятие. - Екатеринбург: Изд-во Урал. ун-та. 2011. - 172 с.

11. Новиков Л.А. Художественный текст и его анализ. М.: Русский язык. 2008. 230 с.

12. Федеральный государственный образовательный стандарт высшего образования. Зарегистрировано в Минюсте России 15 марта 2018 г. N 50362 https://omgpu.ru/sites/default/files/files/basic/programmy-bakalavriata-fgos3/44.03.01_pedagogicheskoe_obrazovanie.pdf (дата обращения: 17.05.2020 г.).

13. Фоменко Ю.В. Типы речевых ошибок. Новосибирск. 2010. - 60 с.

Чадина Ю.А. Комплексный анализ текста как метод развития творческих способностей учащихся // Вестник Московского городского педагогического университета, 2011. № 2 (7). - С. 100 - 107. 